\title{
CONTROL OF TREHALASE SYNTHESIS IN NEUROSPORA CRASSA ${ }^{1}$
}

\author{
David L. Hanks ${ }^{2}$ and A. S. Sussman \\ Department of Botany, University of Michigan, Ann Arbor
}

A B S T R A O T

\begin{abstract}
When an aconidial strain (STL6A) of Neurospora crassa is grown on carbon sources such as glucose, maltose, sucrose, etc., trehalase activity per unit weight of mycelium is very low. By contrast, media containing arabinose, glutamic acid, glycine, etc., which support growth only poorly, produce mycelium with very high trehalase activity. Retarding growth limiting the supply of a necessary nutrient, altering the $p \mathrm{H}$ and temperature, or adding toxic substances, however, does not derepress trehalase activity. Repression and derepression of trehalase was found to be reversible through the transfer of cultures to appropriate media. It is likely that the increase in trehalase activity results from de novo synthesis because labeled enzyme can be isolated from acrylamide gels after isolation from medium containing $\mathrm{C}^{14}$-labeled leucine and after purification by other means. These experiments are interpreted in terms of catabolite repression which may be correlated with events during growth and conidiation.
\end{abstract}

IN A PREvious paper Hanks and Sussman (1969) described variations in trehalase activity in relation to growth and conidiation of Neurospora crassa and demonstrated that enhanced activity does not appear until some time after the initiation of conidiation; hence this enzyme does not play a casual role in this process. Moreover, it was observed that under conditions of suppressed conidiation, or in aconidial mutants, trehalase activity remains low until late in the growth cycle after which an increase occurs. Thus trehalase formation may be dependent upon conidiation, and the regulatory mechanism responsible for the control of enzyme synthesis might be affected by this process. $A$ clue was provided by the fact that although abundant conidia are formed in media with sugar concentrations as high as $8 \%$, trehalase formation is delayed considerably under these circumstances. Therefore, it appeared as though trehalase activity might be controlled by sugar concentration and the following studies were designed to investigate this possibility further.

Materials AND Methods-Strain 69-1113A of Neurospora crassa was the standard with which most of the experiments were performed. Mutant strains used included fluffyish (STL6A, aconidial), inos (89601A, inositol-requiring), fluffy (LA), skin (B106a, aconidial), scumbo (5801a), and fluffyoid (P628a) obtained from the Fungal Genetics Stock Center; arg-12 (UM107A, arginine-requiring) and pan-2 (B-2A, pantothenate-

\footnotetext{
${ }^{1}$ Received for publication 25 March 1969.

This study was supported by a N.J.H. Predoctoral Fellowship and constitutes a portion of the thesis submitted as a requirement for the Ph.D. degree of the primary author.

2 Present address: Department of Science, Northeast Missouri State College, Kirksville, Mo.
}

requiring) were obtained through the courtesy of Dr. R. H. Davis, University of Michigan.

Preparation of inocula, methods of culture and harvest and the determination of trehalase activity were as described by Hanks and Sussman (1969). One unit of activity is defined as that amount of enzyme which produces $1 \mu \mathrm{g}$ of glucose in $30 \mathrm{~min}$ at $37 \mathrm{C}$.

Labeling experiments were performed by introducing $5.0 \mu \mathrm{c}$-of $\mathrm{C}^{14}$-labeled $\mathrm{L}$-leucine (obtained from Schwartz Bioresearch Inc., Orangeburg, N.Y.) into the medium of growing cultures of strain $69-1113 \mathrm{~A}$. After $24 \mathrm{hr}$ the mycelium was harvested and the enzymes extracted as described previously (Hanks and Sussman, 1969) and the extract clarified by centrifugation at 1,500$2,000 \times g$. Proteins from aliquots of the supernatant fraction were separated by acrylamide disc electrophoresis (Ornstein and Davis, 1962). The gels were stained for trehalase using the method of Eilers et al. (1964) and were divided into $0.5-\mathrm{cm}$ sections, each of which was placed in $15 \mathrm{ml}$ of scintillation fluid (Bruno and Christian, 1961). All determinations of radioactivity were carried out with a Packard Tri-Carb series $314 \mathrm{C}$ single channel liquid scintillation spectrometer $2 \mathrm{hr}$ after the introduction of the gel sections into the fluid.

Results-If the sucrose in the medium in which strain STL6A, an aconidial mutant, is grown is replaced by a $2 \%$ solution of a variety of other sugars or amino acids, an interesting correlation between growth rate and trehalase activity is observed (Fig. 1). Carbon sources such as glucose, maltose, sucrose, mannose or fructose, which permit rapid mycelial growth, elicit only low levels of trehalase activity. By contrast, growth in media containing arabinose, 


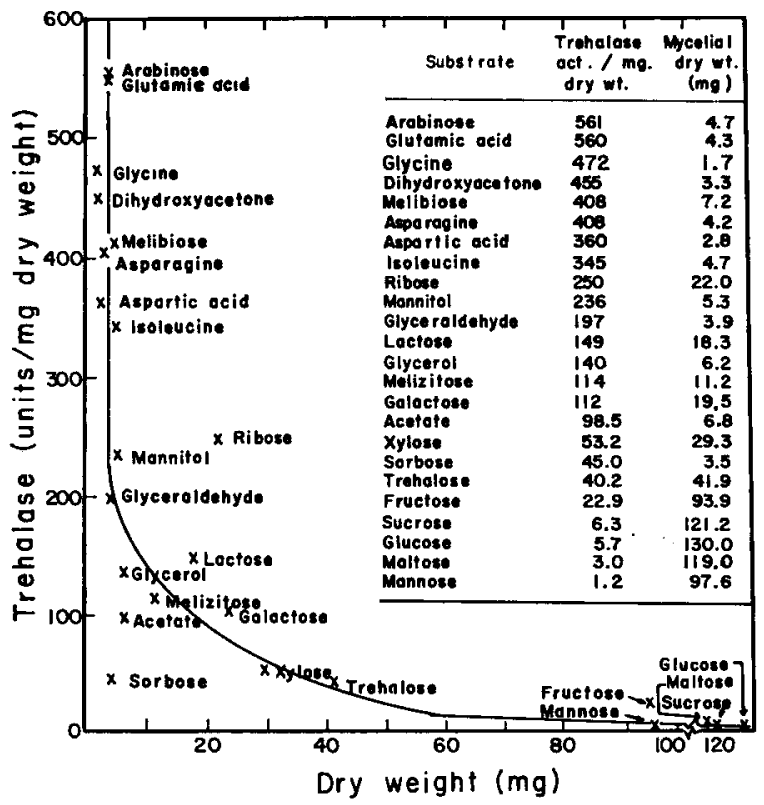

Fig. 1. The effect of various sugars and amino acids upon growth rate and trehalase activity using aconidial mutant, strain STL6A. All cultures were harvested and assayed after 5 days' growth.

glutamic acid, glycine, dihydroxyacetone, etc., is very slow yet trehalase activity is high. Also, those carbon sources that permit an intermediate rate of growth such as galactose, melezitose, etc., exhibit an intermediate level of trehalase activity. That this effect is not restricted to strain STL6A is shown by experiments in which aconidial and slowly conidiating strains were grown on sucrose, mannitol and arabinose. As Table 1 shows, trehalase activity varies inversely with the amount of growth in every one of the strains tested.

If strain STL6A is grown for 5 days in a medium containing from $0.1-0.5 \%$ sucrose instead of the standard $2 \%$, the same relationship between growth rate and enzyme activity is found (Fig. 2). Furthermore, when the carbon supply is completely removed from the growth medium, the effect is even more striking. Three-day-old mycelial mats were removed from the standard growth medium, rinsed thoroughly in distilled water and incubated at $37 \mathrm{C}$ in standard buffer which was filled with absorbent cotton to hold the mat on the surface. As shown in Fig. 3, trehalase activity increased approximately fivefold during a 6-hr incubation period.

The reversible effect of substrate upon trehalase activity was also demonstrated (Fig. 4). Cultures of strain STL6A grown for 4 days in $2 \%$ mannitol produce little mycelial growth but exhibit high trehalase activity. At the end of the 4th day, enough sucrose was added to make a $2 \%$ solution. During the next 4 days, the growth rate increased rapidly while trehalase activity rapidly decreased to the level commonly found in sucrose.

The effects of variations in temperature and $p \mathrm{H}$ upon growth and trehalase activity are shown in Table 2. Lowering of temperature sufficient to reduce the growth rate nearly 100 -fold resulted in only slightly increased activity. Likewise, extremes of $p \mathrm{H}$ (Table 2) or the presence of toxic analogues (Table 3), though reducing growth, had little effect upon trehalase activity. (Cultures used to supply the data for Tables 2,3 were grown under standard conditions with the exception of the variations noted.)

To check further the effects of growth retardation alone upon trehalase activity, a series of auxotrophic mutants were grown for 5 days in standard growth medium supplemented with limiting amounts of the required metabolite (Table 4). An inositol-less strain (89601A) was grown in 1/10 and 1/100 optimal inositol concentrations. Under these conditions mycelial growth was very slow, yet no significant increase in trehalase activity was observed. In addition, an arginine-requiring mutant, strain UM107A, and a pantothenic acid-requiring mutant, strain B2A, were grown in limiting concentrations of arginine and calcium pantothenate, respectively. In each case trehalase activity apparently was unaffected even though the growth was greatly reduced.

Mechanism through which trehalase activity appears-The appearance of increased levels of trehalase in mycelium following conidiation or

TABLE 1. Effects of sucrose, mannitol and arabinose upon growth rate and trehalase activity

\begin{tabular}{|c|c|c|c|c|c|c|}
\hline \multirow[b]{2}{*}{ Strain } & \multicolumn{2}{|c|}{ Sucrose } & \multicolumn{2}{|c|}{ Mannitol } & \multicolumn{2}{|c|}{ Arabinose } \\
\hline & $\begin{array}{c}\text { Dry wt } \\
\text { (mg) }\end{array}$ & $\begin{array}{c}\text { Trehalase } \\
\text { (units/mg } \\
\text { dry wt) }\end{array}$ & $\begin{array}{c}\text { Dry wt } \\
\quad(\mathrm{mg})\end{array}$ & $\begin{array}{c}\text { Trehalase } \\
\text { (units/mg } \\
\text { dry wt) }\end{array}$ & $\begin{array}{c}\text { Dry wt } \\
(\mathrm{mg})\end{array}$ & $\begin{array}{c}\text { Trehalase } \\
\text { (units/mg } \\
\text { dry wt) }\end{array}$ \\
\hline B106a & 49.1 & 3.9 & 19.0 & 82.1 & 10.2 & 108.8 \\
\hline $5801 a$ & 87.4 & 1.0 & 16.8 & 169.0 & 3.9 & 238.4 \\
\hline $\mathrm{I}, \mathrm{A}$ & 113.6 & 20.9 & 45.7 & 179.4 & 15.9 & 231.4 \\
\hline P628a & 225.0 & 24.9 & 72.0 & 160.6 & 17.9 & 268.2 \\
\hline STL6A & 121.2 & 6.3 & 5.3 & 236.0 & 4.7 & 561.0 \\
\hline
\end{tabular}




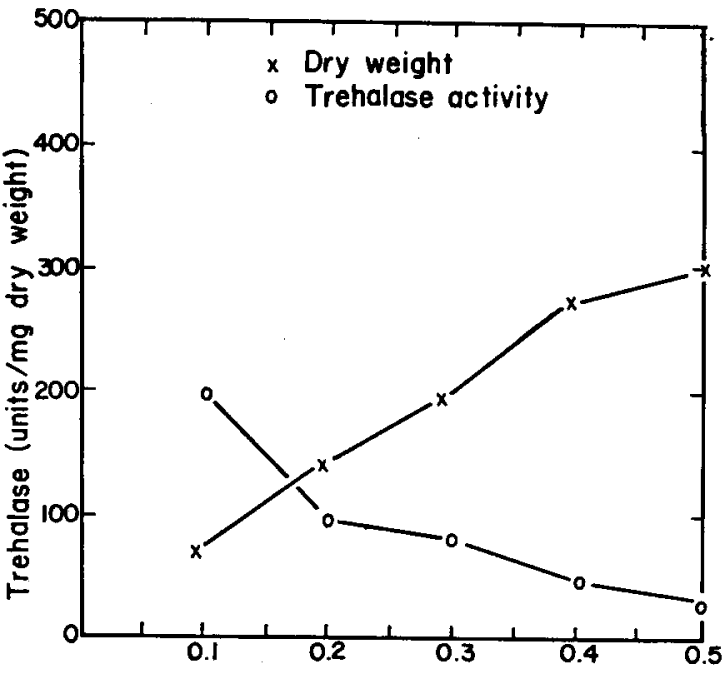

2

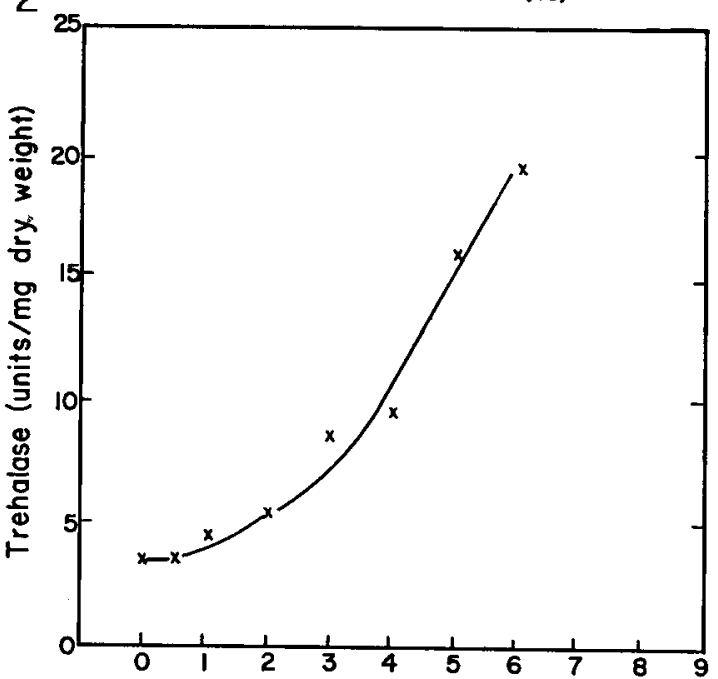

3

Incubation time (hours)

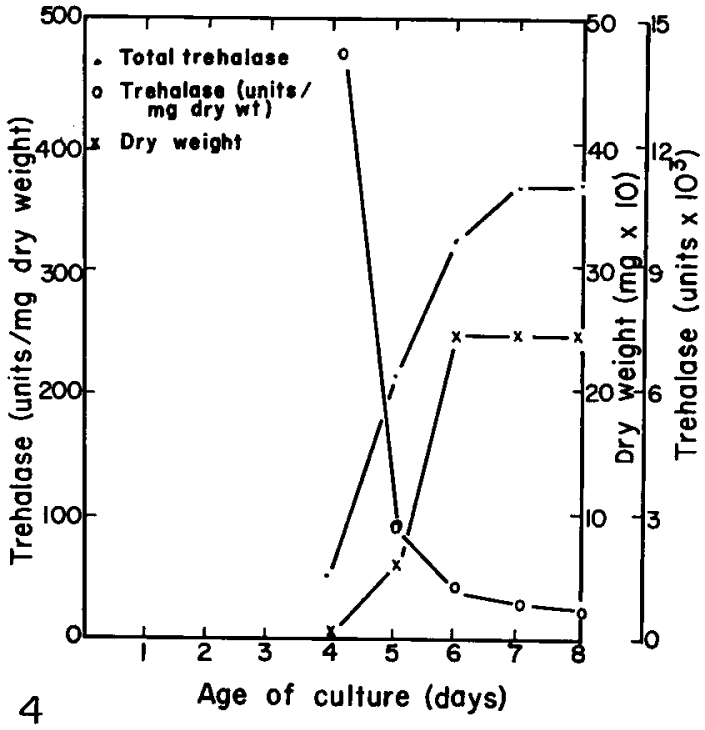

TABLE 2. Effects of temperature and $p H$ upon the growth rate and trehalase activity

\begin{tabular}{cccc}
\hline Temperature & $\begin{array}{c}p \text { H of } \\
\text { medium }\end{array}$ & $\begin{array}{c}\text { Trehalase } \\
\text { (units/mg } \\
\text { dry wt) }\end{array}$ & $\begin{array}{c}\text { Dry wt } \\
\text { (mg) }\end{array}$ \\
\hline $24 \mathrm{C}$ & 6.5 & 6.9 & 1.069 \\
$7 \mathrm{C}$ & 6.0 & 28.8 & 1.3 \\
$24 \mathrm{C}$ & 2.0 & 32.7 & 1.1 \\
$24 \mathrm{C}$ & 3.0 & 15.8 & 25.3 \\
$24 \mathrm{C}$ & 9.0 & 28.5 & 0.7 \\
$24 \mathrm{C}$ & 10.0 & 22.6 & 0.7 \\
\hline
\end{tabular}

TABd.E 3. Effects of toxic metabolites upon growth rate. and trehalase astivity

\begin{tabular}{lccc}
\hline \hline \multicolumn{1}{c}{ Analogue } & $\begin{array}{c}\text { Concentration } \\
\text { used }\end{array}$ & $\begin{array}{c}\text { Trehalase } \\
\text { (units/mg } \\
\text { dry wt) }\end{array}$ & $\begin{array}{c}\text { Dry wt } \\
\text { (mg) }\end{array}$ \\
\hline D-tyrosine & $0.0 \mathrm{~g} /$ liter & 6.9 & 106.9 \\
& $0.25 \mathrm{~g} /$ /iter & 10.5 & 31.7 \\
& $0.50 \mathrm{~g} /$ /iter & 5.8 & 30.6 \\
& $0.75 \mathrm{~g}$ /liter & 10.3 & 29.0 \\
& & & \\
D-phenylalanine & $0.0 \mathrm{~g} /$ /liter & 6.9 & 106.9 \\
& $0.25 \mathrm{~g} /$ liter & 7.1 & 11.5 \\
& $0.50 \mathrm{~g} /$ /liter & 8.8 & 14.3 \\
& $0.75 \mathrm{~g} /$ liter & 0.77 & 6.5 \\
\hline
\end{tabular}

TABLF 4. Effects of growth-limiting concentrations of required metabolites upon growth rate and trehalase activity

\begin{tabular}{lccr}
\hline \hline & $\begin{array}{c}\text { Concentration } \\
\text { of required } \\
\text { metabolite }\end{array}$ & $\begin{array}{c}\text { Trehalase } \\
\text { (units/mg } \\
\text { dry wt) }\end{array}$ & Dry wt \\
\hline 89601A (inositol- & $5 \mu \mathrm{g} /$ /liter & 10.8 & 107.9 \\
less) & & & \\
& $0.5 \mu \mathrm{g} /$ /liter & 0.96 & 10.4 \\
B-2A (Pantothenate- & $400 \mu \mathrm{g} /$ liter & 55.0 & 112.0 \\
requiring) & & & \\
& $300 \mu \mathrm{g} /$ liter & 37.0 & 117.0 \\
& $200 \mu \mathrm{g} /$ /liter & 23.0 & 85.7 \\
& $100 \mu \mathrm{g} /$ liter & 20.0 & 8.8 \\
UM107A (Arginine- & $100 \mathrm{mg} /$ liter & 37.5 & 44.7 \\
requiring) & & & \\
& $50 \mathrm{mg} /$ liter & 28.5 & 26.3 \\
& $10 \mathrm{mg} /$ liter & 36.3 & 4.2 \\
& $5 \mathrm{mg} /$ liter & 38.4 & 1.9 \\
\hline
\end{tabular}

Fig. 2-4.-Fig. 2. The effect of sucrose concentration in the growth medium on growth rate and trehalase activity using strain STL6A.-Fig. 3. The effect of complete removal of carbohydrates from the growth medium on trehalase activity using strain STL6A. Three-day-old cultures were removed from standard growth medium, washed, and incubated in standard buffer solution.Fig. 4. Reversal of trehalase derepression in the mycelium of strain STL6A using mannitol and sucrose as substrates. Cultures were grown in mannitol for 4 days after which $2 \%$ sucrose was added to the growth medium. 
TABLE 5. Tests for the presence of a trehalase inhibitor in extracts of cultures exhibiting low activity

\begin{tabular}{llr}
\hline \multicolumn{1}{c}{ Origin of extract } & & $\begin{array}{r}\text { Trehalase } \\
\text { (units/ml) }\end{array}$ \\
\hline (a) Strain STL6A, 4 days old & & 29 \\
(b) Strain 69-1113A, 7 days old (shaken) & 219 \\
(c) Dilution of purified trehalase & (observed) & 1153 \\
(d) 1:1 mixture of (a) and (b) & 118 \\
& (expected) & 124 \\
(e) 1:1 mixture of (a) and (c) & (observed) & 596 \\
& (expected) & 591 \\
& & \\
(a) Strain 69-1113A, 3 days old (shaken) & 27 \\
(b) Strain 69-1113A, 4 days old (shaken) & 23 \\
(c) Strain 69-1113A, 8 days old (shaken) & 337 \\
(d) Dilution of purified trehalase & 1290 \\
(e) 1:1 mixture of (a) and (c) & (observed) & 188 \\
& (expected) & 182 \\
(f) 1:1 mixture of (a) and (d) & (observed) & 681 \\
& (expected) & 659 \\
(g) 1:1 mixture of (b) and (c) & (observed) & 172 \\
& (expected) & 180 \\
(h) 1:1 mixture of (b) and (d) & (observed) & 652 \\
& (expected) & 657 \\
\hline
\end{tabular}

the limiting or depletion of substrate may involve any of the following mechanisms: de novo synthesis, the removal of an inhibitor, or the conversion of a precursor into the enzyme in a manner analogous to the trypsinogen-trypsin transformation. Therefore, the following experiments were designed to determine the means through which trehalase activity arises during development in Neurospora so that the level at which control is exerted can be specified.

An inhibitor of trehalase was sought by mixing extracts of 3- and 4-day-old shaken cultures of strain 69-1113A with equal volumes of extracts of 8-day-old cultures of the same strain and purified trehalase. Following an incubation period of 30 min at room temperature, no depression of trehalase activity in either case was detected (Table 5). A similar experiment was performed with an extract of strain STL6A and similar results were obtained (Table 5).
De novo synthesis of the enzyme was investigated by the use of inhibitors of protein synthesis at the level of transcription (actinomycin D) and translation (chloramphenicol and cyclohexamide). Shaken cultures were used and the inhibitors were added at various times after inoculation; all cultures were harvested after 8 days of incubation. Chloramphenicol, in concentrations as high as $10^{-3} \mathrm{M}$, had no effect upon either growth or trehalase formation. On the other hand, $50 \mathrm{~g}$ per $\mathrm{ml}$ actinomycin $\mathrm{D}$ and $1 \times 10^{-4} \mathrm{~m}$ cyclohexamide inhibited both processes (Table 6). In all cases the addition of either actinomycin $\mathrm{D}$ or cyclohexamide seemingly arrested further development of trehalase activity. In fact, in most instances a loss in trehalase activity was noted following introduction of the antibiotic.

Labeling experiments were performed wherein $5 \mu \mathrm{c}$ of $\mathrm{C}^{14}$-labeled L-leucine were incorporated in the medium in which 1- and 6-day-old cultures of strain $69-1113 \mathrm{~A}$ were grown under standard conditions and in that of 5-day-old shaken cultures of the same strain. After $24 \mathrm{hr}$ extracts were fractionated by disc electrophoresis and the gels stained for trehalase. Then the gels were cut into $0.5-\mathrm{cm}$ sections and the radioactivity in each determined. Under conditions where trehalase activity remains low (2-day-old cultures of strain 69-1113A grown under standard conditions), the distribution of radioactivity is spread rather uniformly over the entire acrylamide gel (Table 7). However, when the label is added to the medium during the time when trehalase activity increases rapidly (7-day-old cultures of strain 69-1113A grown under standard conditions or 6-day-old shaken cultures of the same strain), high levels of radioactivity are found to accumulate in the section of the gel which stains for the enzyme.

Trehalase has been shown to remain stable when heated to $60 \mathrm{C}$ (Hill and Sussman, 1963). Therefore, to test whether label is incorporated into trehalase and not into another molecule that may have migrated at the same rate, extracts from 6-day-old shaken cultures of strain 69-1113A were heated to 50 and $60 \mathrm{C}$ for $15 \mathrm{~min}$ and run on

TABLE 6. Effect of metabolic inhibitors upon trehalase activity

\begin{tabular}{|c|c|c|c|c|c|c|}
\hline \multirow[b]{2}{*}{$\begin{array}{c}\text { Age in days } \\
\text { when inhibitor } \\
\text { added }\end{array}$} & \multicolumn{3}{|c|}{ Total trehalase activity (units) } & \multicolumn{3}{|c|}{ Dry weight (mg) } \\
\hline & $\begin{array}{c}\text { Actino- } \\
\text { mycin D } \\
(50 \mu \mathrm{g} / \mathrm{ml})\end{array}$ & $\begin{array}{c}\text { Cyclohex- } \\
\text { amide } \\
\left(1 \times 10^{-4} \mathrm{M}\right)\end{array}$ & $\begin{array}{c}\text { Control } \\
\text { (harvested } \\
\text { on day } \\
\text { inhibitor } \\
\text { added) }\end{array}$ & Actinomycin D & Cyclohexamide & Control \\
\hline 3 & 400 & 500 & 700 & 80.8 & 89.6 & 187 \\
\hline 4 & 3300 & 3600 & 2300 & 174.0 & 154.2 & 234 \\
\hline 5 & 8900 & 13900 & 15500 & 97.9 & 89.1 & 245 \\
\hline 6 & 8400 & 6700 & 35500 & 110.8 & 92.6 & 197 \\
\hline 7 & 41900 & 33200 & 64500 & 164.0 & 101.4 & 226 \\
\hline 8 & & & 67400 & & & 200 \\
\hline
\end{tabular}


TABLE 7. Relationship between trehalase and the distribution of $C^{14}$-labeled L-leucine using disc electrophoresis

\begin{tabular}{|c|c|c|c|c|c|c|c|c|c|c|c|}
\hline \multirow[b]{2}{*}{ Growth conditions } & \multirow{2}{*}{$\begin{array}{c}R_{F} \text { of } \\
\text { tre- } \\
\text { halase }\end{array}$} & \multirow{2}{*}{$\begin{array}{c}\text { Age } \\
\text { when } \\
\text { harvested }\end{array}$} & \multirow{2}{*}{$\begin{array}{l}\text { Percent } \\
\text { acryl- } \\
\text { amide }\end{array}$} & \multirow[b]{2}{*}{1} & \multirow[b]{2}{*}{2} & \multicolumn{4}{|c|}{$\begin{array}{l}\text { epm of each of the } 0.5-\mathrm{cm} \\
\text { sections of gel } \\
\text { direction of solvent front }\end{array}$} & \multirow[b]{2}{*}{7} & \multirow[b]{2}{*}{8} \\
\hline & & & & & & 3 & 4 & 5 & 6 & & \\
\hline Standard conditions & 0.57 & 2 & 7.5 & 358 & 1598 & 2360 & 4401 & $3519 \mathrm{a}$ & 2739 & 1817 & 2391 \\
\hline Standard conditions & 0.57 & 7 & 7.5 & 354 & 306 & 338 & 477 & 884 & 380 & 442 & 581 \\
\hline Shaken culture & 0.57 & 6 & 7.5 & 453 & 204 & 638 & 1281 & 2562 & 489 & 1123 & 832 \\
\hline $\begin{array}{l}\text { Shaken culture } \\
\qquad(60 \mathrm{C} \text { for } 15 \mathrm{~min})\end{array}$ & 0.57 & 6 & 7.5 & 11 & 26 & 60 & 28 & 1542 & 258 & 47 & 348 \\
\hline $\begin{array}{l}\text { Shaken culture } \\
\quad(50 \mathrm{C} \text { for } 15 \mathrm{~min})\end{array}$ & 0.57 & 6 & 7.5 & 90 & 282 & 151 & 464 & 1147 & 491 & 128 & 200 \\
\hline Shaken culture & 0.43 & 6 & 15.0 & 22498 & 20842 & 11443 & 47922 & 11808 & 14479 & 4786 & 6758 \\
\hline Shaken culture & 0.14 & 6 & 30.0 & 34290 & 11992 & 6355 & 2805 & 5831 & 16089 & 7977 & 3693 \\
\hline
\end{tabular}

a Value in italics where trehalase stain appeared.

gels as above. As can be seen in Table 7, the amount of label in the trehalase-containing section is considerably greater than in the other sections. Moreover, when the $R_{F}$ of trehalase was reduced from 0.5 to 0.43 and 0.14 by changing the amount of acrylamide from the usual $7.5 \%$ to 15 and $30 \%$ respectively, most of the label accumulated in the sections of gel which contained the trehalase, regardless of the gel strength (Table 7).

Another test to determine whether the radioactivity associated with the stained portion of the gel was in trehalase was performed by eluting the trehalase-containing section from several gels. This was accomplished by staining a single marker gel for trehalase and eluting the enzyme from comparable sections of other gels. Elution was carried out in standard buffer and the eluate was dialyzed overnight against the same buffer, concentrated under vacuum, and subjected to some of the steps in the purification procedure developed by Hill and Sussman (1963). First, the eluate was heated to $60 \mathrm{C}$ for $15 \mathrm{~min}$ after which the precipitate was removed by centrifugation. Precipitation of nucleic acids was accomplished by the addition of $1.0 \mathrm{M} \mathrm{NaOH}$ and $1.0 \mathrm{M} \mathrm{MnSO}_{4}$ $(0.1 \mathrm{ml}$ of each per $10 \mathrm{ml}$ eluate). The final step involved salting out with $\left(\mathrm{NH}_{4}\right)_{2} \mathrm{SO}_{4}$ after which

TABLE 8. Correlation between trehalase activity and radioactivity of the eluate from trehalase-containing sections of acrylamide gels

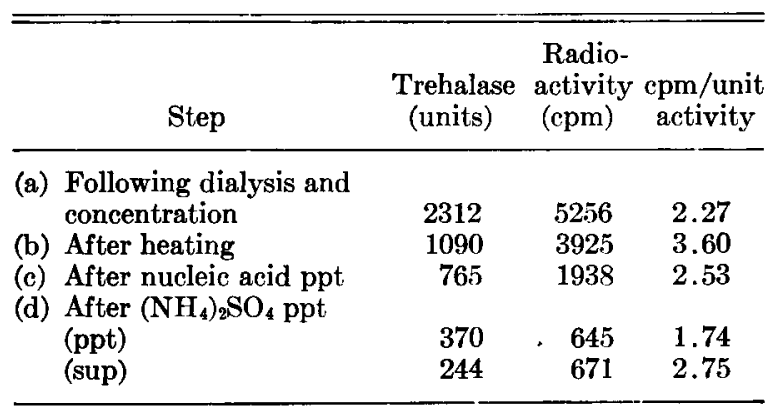

the precipitate was redissolved in cold standard buffer and dialyzed thoroughly. Enzyme activity and radioactivity were followed through each of these steps with results that show a close parallel between both parameters at each step of purification (Table 8).

Discussion - Our previous results (Hanks and Sussman, 1969) have shown that aconidial or poorly conidiating strains of Neurospora crassa do not form trehalase until the growth rate diminishes, probably because of the depletion of the exogenous sucrose supply. Therefore, derepression of trehalase activity may be attributed either to the retardation of mycelial growth, exhaustion of sucrose, or to a combination of these and other factors. In contrast, the increase in trehalase activity that occurs in heavy conidiators, while following upon the arrest of growth, does not await complete depletion of sucrose from the medium. This is the only case in our experience where derepression occurs in relatively high concentrations of this sugar.

However, derepression of trehalase also is observed in the aconidial strain, STL6A, in carbon sources which permit only limited growth (Fig. 1). In fact, an inverse relationship appears to exist between the amount of growth in a carbon source and trehalase activity in several strains of Neurospora (Table 1).

Repression and derepression in these cultures were found to be reversible. Thus, initial growth in $2 \%$ mannitol yields little growth yet trehalase activity is high. The addition of $2 \%$ sucrose to 4-day-old cultures in mannitol increases the rate of growth but reduces the trehalase activity per unit weight to the range usually found in sucrosegrown cultures (Fig. 4). The opposite response occurs when rapidly growing cultures exhibiting low trehalase activity are removed from the standard growth medium and placed in standard buffer. Under these conditions trehalase activity per unit weight rapidly increases (Fig. 3). 
That derepression does not result simply from growth retardation is shown by experiments wherein growth was limited by vitaminor amino acid-deprivation (Table 4), $p \mathrm{H}$ and temperature alteration (Table 3), or the addition of toxic substances (Table 5).

It is likely that increased trehalase activity results from de novo synthesis of the enzyme and not to the removal of an inhibitor. Thus, $\mathrm{C}^{14}$-labeled $\mathrm{L}$-leucine is readily incorporated into trehalase which is localizable on acrylamide gels when enzyme activity is increasing. By contrast, when trehalase activity is not increasing, as in young cultures, label is uniformly distributed on gels. Furthermore, the addition of cyclohexamide and actinomycin $\mathrm{D}$ to the medium prior to the time when increased trehalase activity usually appears results in greatly reduced activity. Finally, the activity of purified trehalase, or of crude extracts containing high activity, was not diminished when mixed with crude extracts of strain STL6A which exhibits only low activity.

Glucose is known to repress enzyme activity by several means, including "inactivation repression" (Ferguson, Boll, and Holzer, 1966), "transient repression" (Paigen, 1966; Tyler, Loomis, and Magasanik, 1967), and "catabolite repression" (Horowitz and Metzenberg, 1965). Inactivation repression results in the loss of enzyme activity after the addition of the repressor, as in the case of malate dehydrogenase in yeast. However, the data in Fig. 4 indicate that, although the trehalase activity per unit weight decreases upon the addition of glucose via hydrolysis of sucrose, the total activity increases; thus it is unlikely that inactivation repression is involved in this system in Neurospora. Furthermore, transient repression does not require catabolism of the compound added, whereas our experiments (see Fig. 1) suggest that the substances most active in repression also seem to be the best substrates.

Therefore, these data suggest that trehalase activity is controlled by catabolite repression, as is true of several other enzymes involved in carbon and energy metabolism (Mandelstam, 1962; Horowitz and Metzenberg, 1965). Among the hypotheses to explain the mechanism of catabolite repression is that of Cohn and Monod (1953) who suggest that the sugar may prevent the entrance of an inducer into the cell; in fact, the data of Adhya and Echols (1966) and Lengeler (1966) support this explanation in the case of the galactose enzymes of $E$. coli. On the other hand, Neidhart and Magasanik (1956) and Prevost (1967) argue that glucose is metabolized so readily that intermediates are formed more quickly than they are metabolized, thereby forming intracellular pools that may control enzyme synthesis through feedback inhibition.

The latter hypothesis seems the most plausible in the case of catabolite repression in Neurospora.
Thus mycelial growth in the absence of conidiation continues until the sugar is depleted and concomitantly endogenous pools probably are generated, thereby repressing trehalase formation. After depletion of the exogenous sugar supply, pool sizes very likely diminish and allow derepression to occur. When conidiation occurs, derepression of mycelial trehalase is observed prior to the exhaustion of exogenous sugar, perhaps because the requirement for intermediates is so great during spore formation that pool sizes decrease, even in the presence of residual external substrate. Furthermore, the data in Fig. 1 could be explained on the basis that carbon sources that are only slowly utilized are not likely to form extensive pools of intermediates, thereby reducing the extent of catabolite repression. This is in accord with the findings of McFall and Mandelstam (1963) that the degree of repression exhibited by the substances they used was directly related to their effectiveness as a substrate. Moreover, when "growth is restricted by poisons or other means that do not affect pool sizes, derepression does not occur.

A related enzyme in Neurospora that appears to be subject to catabolite repression is invertase (Metzenberg, 1962). As a result of data obtained from the study of a mutant producing abnormally large amounts of the enzymes, Metzenberg suggested that trehalase and invertase are coordinately repressed, perhaps through regulation at a single locus. Work by Hill and Sussman (1964), however, indicates that the levels of the two enzymes are not proportionately altered under certain circumstances and at least two isozymes of invertase occur (Eilers et al., 1964; Metzenberg, 1964).

Moreover, the results in the previous paper (Hanks and Sussman, 1969) disclose that the ratio of trehalase activities in wild as compared with aconidial strains is much greater than that of invertase, showing once again that the activities are probably not strictly coordinated.

\section{LITERATURE CITED}

Adhy a, S., And H. Echols. 1966. Glucose effect and the galactose enzymes of Escherichia coli: correlation between glucose inhibition of induction and inducer transport. J. Bacteriol. 92: 601-608.

Bruno, G. A., And J. F. Christian. 1961. Determination of carbon-14 in aqueous bicarbonate solutions by liquid scintillation counting techniques. Anal. Chem. 33: 1216-1218.

Cohn, M., and J. Monon. 1953. Specific inhilition and induction of enzyme biosynthesis. Symp. Soc. Gen. Microbiol. 3: 132-149.

Eilers, F. I., J. Alien, E. P. Hill, and A. S. Sussman. 1964. Localization of disaccharidases in extracts of Neurospora after electrophoresis in polyacrylamide gels. J. Histochem. Cytochem. 12:448-450.

Ferguson, J. J., M. Boll, aND H. Hotzer. 1966. Yeast malate dehydrogenase: Enzyme inactivation 
in catabolite repression. European J. Biochem. 1: 21-25.

Hanks, D. L., Ann A. S. Sussman. 1969. The relation between growth, conidiation and trehalase activity in Neurospora crassa. Amer. J. Bot. 56: 1152-1159.

Hili, E. P., ANd A. S. Sussman. 1963. Purification and properties of trehalase(s) from Neurospora. Arch. Biochem. Biophys. 102: 389-396.

- AND - - 1964. Development of trehalase and invertase activity in Neurospora. J. Bacteriol. 88: $1556-1566$

Horowitz, N. H., AND R. L. Metzenberg. 1965. Biological aspects of genetics. Annu. Rev. Biochem. 34: 527-564.

LENGGLER, J. 1966. Untersuchungen zum Glukose. Effect der Synthese der Galactose-Fnzyme von Escherichia coli. Z. Vererbungsl. 98: 203-229.

Mandelstam, J. 1962. The repression of constitutive $\beta$-galactosidase in Escherichia coli by glucose and other substrates. Biochem. J. 82: 489-493.

McFall, E., AND J. Mandelstam. 1963. Specific metabolic repression of induced enzymes in Escherichia coli. Nature 197: 880 .

Metzenberg, R. L. 1962 . A gene affecting the repression of invertase and trehalase in Neurespora. Arch. Biochem. Biophys. 96: 468-474.

-2. 1964. Enzymically active subunits of Neurospora invertase. Biochim. Biophys. Acta. 89: 291-302.

Neidhardt, F. C., and B. Magasanik. 1956. Inhibitory effects of glucose on enzyme formation. Nature 178: 801-802.

Ornstein, L., ani B. J. Davis. 1962. Dise electrophoresis. Distillation Products Inc., Rochester, N. Y.

Paigen, K. 1966. Phenomenon of transient repression in Escherichia coli. J. Bacteriol. 91: 1201-1209.

Prevost, C. 1967. Pool sizes of metabolic intermediates and their relation to glucose repression of $\beta$-galactosidase synthesis in Escherichia coli. Biochem. J. 103: 349-357.

Tyler, B., W. F. Loomis, JR., and B. Magasanik. 1967. Transient repression of the lac operon. J. Bacteriol. 94: 2001-2011. 